\title{
Review of Cortical Bone Trajectory: Evidence of a New Technique
}

\author{
Juan Delgado-Fernandez, Maria Ángeles García-Pallero, \\ Guillermo Blasco, Paloma Pulido-Rivas, Rafael, G. Sola \\ Division of Neurosurgery, Department of Surgery, University Hospital La Princesa, Madrid, Spain
}

\begin{abstract}
This article summarizes recent evidence on the cortical bone trajectory (CBT) obtained from published anatomical, biomechanical, and clinical studies. CBT was proposed by Santoni in 2009 as a new trajectory that can improve the fixation of pedicle screws in response to screw loosening in osteoporotic patients. Recently, research interest has been growing with increasing numbers of published series and frequent reports of new applications. We performed an online database search using the terms "cortical bone trajectory," "pedicle screw," "CBT spine," "CBT fixation," "MISS CBT," and "traditional trajectory." The search included the PubMed, Ovid MEDLINE, Cochrane, and Google Scholar databases, resulting in an analysis of 42 articles in total. These covered three aspects of CBT research: anatomical studies, biomechanical parameters, and clinical cases or series. Compared to the traditional trajectory, CBT improves pullout strength, provides greater stiffness in cephalocaudal and mediolateral loading, and shows superior resistance to flexion/extension; however, it is inferior in lateral bending and axial rotation. CBT seems to provide better immediate implant stability. In clinical studies, CBT has shown better perioperative results for blood loss, length of stay in hospital, and surgery time; similar or better clinical postoperative scores; and similar comorbidity, without any major fixation system complications due to instrumentation failure or screw misplacement. In addition, advantages such as less lateral exposure allow it to be used as a minimally invasive technique. However, most of the clinical studies were retrospective case series or case-control studies; prospective evidence on this technique is scarce, making a definitive comparison with the traditional trajectory difficult. Nevertheless, we can conclude that CBT is a safe technique that offers good clinical results with similar biomechanical and perioperative parameters to those of the traditional trajectory. In addition, new applications can improve its results and make it useful for additional pathologies.
\end{abstract}

Keywords: Cortical bone trajectory; Traditional trajectory; Pedicle screw; CBT biomechanics; CBT anatomy; CBT complications

\section{Introduction}

Pedicle screw fixation is a standard procedure in spine surgery and the main technique for maintaining spinal stability and biomechanical features in spinal disease. Pedicle screws have been successfully used with good results for multiple pathologies, such as spinal deformities, degenerative diseases, or fractures. However, some complications have been associated with this procedure, with system failure being one of the most important. Incidence of screw loosening has been estimated to range from $1 \%$ to $15 \%$ in non-osteoporotic patients and exceed $60 \%$ in patients with osteoporotic bones [1]; however, the actual incidence of this problem has not yet been confirmed

\footnotetext{
Received Nov 15, 2016; Revised Feb 6, 2017; Accepted Mar 1, 2017

Corresponding author: Juan Delgado Fernández

Division of Neurosurgery, Department of Surgery, University Hospital La Princesa, C/Diego de León 32, 28006, Madrid, Spain

Tel: +34-915202200/17430, Fax: +34-914013582, E-mail: juan.delgado.fdez@gmail.com
} 
[2]. Obtaining a more solid internal fixation is therefore an important issue for spinal surgeons, and various approaches, including changing the screw trajectory, have been proposed with the aim of improving longevity and avoiding such complications $[3,4]$.

In 2009, Santoni et al. [3] proposed a new insertional pathway in place of the traditional trajectory (TT), referred to as the cortical bone trajectory (CBT). The traditional insertional pathway runs through the pedicle axis with a lateral-to-medial trajectory starting at the junction between the transverse process and the lateral wall of the facet and ending at the vertebral body. In contrast, CBT involves a medial-to-lateral direction and a caudocephalad path with the objective of maximizing thread contact with higher-density bone. The aims of this track are to improve the adhesion of the screws in osteoporotic vertebrae and to prevent instrumentation failure [3].

This paper summarizes the biomechanical and clinical studies of CBT published to date and evaluates its possible advantages for daily clinical practice.

\section{Materials and Methods}

A literature search was performed in the PubMed, Ovid Medline, Cochrane, and Google Scholar databases using the search terms "cortical bone trajectory," "CBT spine," "CBT fixation," "MISS CBT," "traditional trajectory," and "pedicle screw." The search included papers published up to May 2016. All retrieved abstracts were analyzed to determine whether they presented relevant information about anatomical, biomechanical, or radiological results in either clinical or cadaveric studies. For those that did, complications, clinical results, and technical and surgical features were recovered from the associated papers for subsequent review. In addition, the reference lists of the identified publications were checked to determine further relevant articles that should be incorporated in the analysis.

\section{Results}

Finally, 42 articles were included in the analysis. These covered three aspects of CBT: anatomical studies, biomechanical parameters, and clinical cases or series. Six of the articles considered anatomical landmarks of CBT with regard to previous citations or possible complications in CBT procedures. Biomechanical parameters were discussed in 13 articles, which considered physical parameters that could show how CBT resulted in improved biomechanical properties compared to TT. Finally, 20 articles and two communications to meetings were analyzed for clinical series and cases. These 42 articles comprised all eligible reports published up to the date the review was finished. No previous review studies were included in the present narrative review.

\section{Biomechanical and anatomical studies}

In 2007, Sterba et al. [5] published a cadaveric study showing that straight screw insertion provided a more stable pedicle screw construct than the pathway parallel to the sagittal plane, because the angled trajectory resulted in lower average total fatigue damage. Previously, RoyCamille et al. [6] had proposed that a vertical trajectory through the pedicle would increase thread contact with the cortical bone at the end point. In this context, Santoni et al. [3] proposed CBT as a way to avoid screw system failure in osteoporotic patients and demonstrated that this trajectory increased resistance in a uniaxial pullout test when compared to traditional screws. Some previous anatomic studies about the limitations of pedicle screw insertion should be considered. Li et al. [7] reviewed 41 computed tomography scans that focused on the height, width, and isthmus inclination of the pedicle, concluding that width was the most important factor for screw placement. They also found that the cortical thickness of the superior and medial walls was generally greater than $2 \mathrm{~mm}$. This could explain why pedicles are more likely to break laterally. This demonstrated that the CBT technique could result in enhanced screw purchase and greater interface strength independent of the trabecular bone mineral density (BMD), because the screws have four points of fixation: between the dorsal cortex and the site of insertion, on the posteromedial and anterolateral pedicle walls, and on the marginal region of the vertebral body wall (Fig. 1) $[4,8]$. Thus, although CBT screws are shorter in length and smaller in diameter than those used with TT, they are in contact with bone surface of higher density. In fact, Mai et al. [9] conducted an observational study that measured BMD (in Hounsfield units) at the theoretical end point in $\mathrm{CBT}$ and TT, demonstrating greater density for CBT, especially in the osteoporotic cohort (Table 1).

Since the introduction of CBT, studies have been conducted to determine its biomechanical characteristics. 

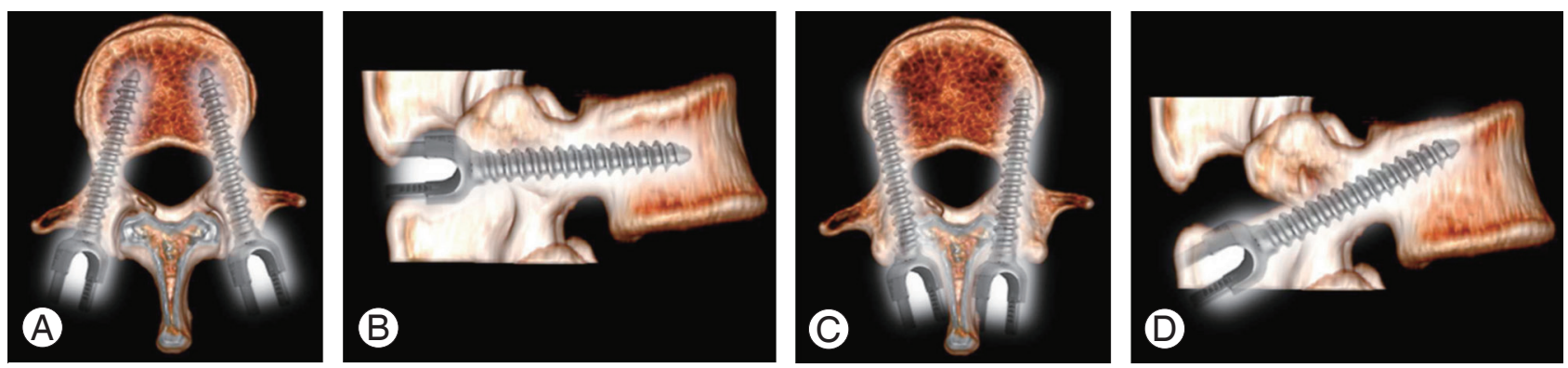

Fig. 1. Comparison of the traditional trajectory $(\mathbf{A}, \mathbf{B})$ and cortical bone trajectory $(\mathbf{C}, \mathbf{D})$. (A, B) Axial and sagittal views of the traditional trajectory following the pedicle axis in a lateral-to-medial trajectory parallel to the superior and inferior endplates. (C, D) Axial and sagittal views of the cortical bone trajectory with a medial-to-lateral disposition and a $25^{\circ}-30^{\circ}$ cranial direction along the inferior border of the pedicle.

Table 1. Summary of anatomical studies for CBT fixation

\begin{tabular}{|c|c|c|c|c|c|}
\hline Author & $\begin{array}{c}\text { Type and } \\
\text { nature of study }\end{array}$ & $\begin{array}{c}\text { No. of } \\
\text { subjects }\end{array}$ & Study design & Parameters & Conclusions \\
\hline $\begin{array}{l}\text { Li et al., } 2004 \\
\text { [7] }\end{array}$ & $\begin{array}{l}\text { Radiological mor- } \\
\text { phometric study } \\
\text { Cohort study } \\
\text { LE: } 4\end{array}$ & 41 Patients & $\begin{array}{l}\text { Ultra high-speed } \\
\text { spiral CT scans of } \\
\text { lumbar spine }\end{array}$ & $\begin{array}{l}\text { Isthmus width, height, area, } \\
\text { isthmus endosteal, isthmus } \\
\text { cortical thickness, inclination, } \\
\text { and pedicle length }\end{array}$ & $\begin{array}{l}\text { Pedicle isthmus is the narrowest } \\
\text { section of the pedicle and especially } \\
\text { the isthmus endosteal is the most } \\
\text { important parameter for transpedicu- } \\
\text { lar procedures. }\end{array}$ \\
\hline $\begin{array}{l}\text { Matsukawa et } \\
\text { al., } 2013 \text { [10] }\end{array}$ & $\begin{array}{l}\text { Radiological mor- } \\
\text { phometric study } \\
\text { Cohort study } \\
\text { LE: } 4\end{array}$ & $\begin{array}{l}100 \text { Patients, } \\
470 \text { vertebrae }\end{array}$ & $\begin{array}{l}\text { A morphometric } \\
\text { measurement of CBT } \\
\text { for the lumbar pedicle } \\
\text { screw insertion using } \\
\text { CT }\end{array}$ & $\begin{array}{l}\text { Diameter, length, lateral angle } \\
\text { to the vertebral sagittal plane, } \\
\text { and cephalad angle to the } \\
\text { vertebral horizontal plane of } \\
\text { the trajectory }\end{array}$ & $\begin{array}{l}\text { The morphology of the pedicle, such } \\
\text { as shape and pedicle axis angle, dif- } \\
\text { fered over the lumbar levels. There } \\
\text { were no differences between each } \\
\text { level of the lateral and cephalad } \\
\text { angles. }\end{array}$ \\
\hline
\end{tabular}

$\begin{array}{ll}\text { Matsukawa et } & \text { Radiological } \\ \text { al., 2014 [11] } & \text { morphometric and } \\ & \text { clinical study } \\ & \text { Cohort study } \\ & \text { LE: } 4\end{array}$

Matsukawa et Radiological al., 2017 [12] morphometric and human cadaveric study Case-control study tebrae LE: 4

$\begin{array}{llll}\begin{array}{l}\text { Mai et al., } \\ \text { 2016 [9] }\end{array} & \begin{array}{l}\text { Observational } \\ \text { anatomic study } \\ \text { Observational } \\ \text { case-control study } \\ \text { LE: } 3\end{array} & \text { 180 Patients } & \begin{array}{l}\text { HU from CT images } \\ \text { were used as a met- } \\ \text { ric for bone mineral } \\ \text { density. }\end{array} \\ \text { Zhang et al., } & \begin{array}{l}\text { Radiological mor- 86 Patients } \\ \text { phometric study } \\ \text { 2016 [13] }\end{array} & \begin{array}{l}\text { 3D-CT lumbosacral } \\ \text { sohort study } \\ \text { LE: } 4\end{array} & \\ & & \end{array}$

CT from 50 CT scans of 50 adults Cephalad angle to the sacral patients; 19 were studied for patients were morphometric meaoperated. surement of sacral trajectory.

\section{CT from $50 \quad 50$ CT scans from} patients; 24 lower thoracic vertecadaveric thoracic verbrae were analysed. Insertional torque was compared in cadaveric vertebrae between CBT and TT. endplate, length of trajectory

The penetrating S-1 endplate technique through the medial entry point is suitable for the connection of lumbar CBT.

Diameter, length and cephalad All morphometric parameters angle. Insertional torque of fixation system. increased from T9-T12. The insertional torque using thoracic CBT was $53.8 \%$ higher than TT.
Hounsfield units were measured at end fixation point for CBT or TT.
Bone mineral density measured by $\mathrm{HU}$ values for the fixation point of the CBT screw is higher than that of the $T$ T. This difference is even more pronounced when comparing osteoporotic and elderly patients.

Distances from insertion start- A decrease in CA1 (26.7 to 22.9 $)$ ing point to inferior, lateral and CA2 $\left(38.7^{\circ}\right.$ to $\left.35.1^{\circ}\right)$ is observed and medial border of inferior from L1 to L5. CA2 in S1 is increased. facet of the cephalad level and Maximum screw diameters from angles formed between screw $\mathrm{L} 1$ to $\mathrm{S} 1$ varies from 4.8 to $7.8 \mathrm{~mm}$. trajectory and sagittal Maximum length $25 \mathrm{~mm}$ is safe for plane, superior endplate (CA1) CBT. Inferior facet of the cephalad and posterior margin of pars level is an attractive bone landmark interarticularis (CA2). for CBT. 
Perez-Orribo et al. [14] published a cadaveric study using screws that were oriented more sagittally and cranially; they did not observe differences in stability compared to traditional pedicle screws, although this orientation gave worse results under axial rotation. Matsukawa et al. [15] showed that CBT provided greater pullout strength, stronger stiffness during cephalocaudal and mediolateral loading, and superior resistance to flexion/extension compared with TT, but that it was inferior with regard to lateral bending and axial rotation. However, different results were obtained when testing spondylolytic vertebrae; CBT showed worse results for all these parameters, making it unsuitable for fixation in these cases [16]. However, as discussed later, CBT has been applied to spondylolytic cases with good outcomes in other series and case-control studies. Range of motion has been compared between CBT and TT in animal [17] and human [14,18] cadaveric studies, finding no differences for flexion/extension, lateral bending, or axial rotation. Calvert et al. [19] used CBT with rescue screws after instrumentation failure; this provided adequate stiffness in flexion/extension and axial rotation. Insertional torque has been previously correlated with pedicle screw pullout strength [20] and Matsukawa et al. [21] investigated how it changed during implant positioning, as an indirect measure of implant stability, founding that it is 1.7 times higher with CBT than with TT. These authors determined, in a multiple regression analysis, that BMD of the femoral neck, screw length within the lamina, and cephalad angle were significant independent factors affecting the torque $[21,22]$. However, in contradiction to previous articles, Akpolat et al. [23] published in 2016 the results of a cadaveric study which concluded that implantation via TT required more cycles for screw loosening and showed better resistance to pullout. Finally, Sansur et al. [24] compared CBT and TT in destabilized cadaveric lumbar spines with osteoporosis, showing that CBT gave better results in the lower spine because of an increase in cancellous bone limit fixation with TT (Table 2) [3,14-19,21-26].

\section{Clinical trials}

Many biomechanical studies have been published since Santoni et al. [3] first proposed CBT, but clinical evidence is still lacking, with no systematic reviews that can provide clear indications for its use. In 2004, Steel et al. [27] were the first to propose mediolateral fixation at a single thoracic level. They described 18 patients with thoracolumbar fractures who underwent operations without major complications. All achieved stable fusion after 6 weeks, without deformity, system failure, or neurological deficit, except for one patient with non-union after 12 months. The authors concluded that this trajectory was safe and effective for fixation and stabilization, and that it was less invasive than anterior or lateral approaches. In 2013, Ueno et al. [28] published a case report of a patient with degenerative scoliosis and osteoporosis who was operated on with a double-trajectory technique (CBT combined with TT at each level), with good morphometric results, no complications, and improvement in daily-life activities 14 months after surgery. Biomechanical studies demonstrated that this technique resulted in greater strength than the TT or CBT constructs for flexion, extension, lateral bending, and axial rotation [26]. Gonchar et al. [29] presented two series at a meeting of the Society for Minimally Invasive Spine Surgery (data not published), one of which compared $100 \mathrm{CBT}$ versus 63 TT patients with pathologies such as degenerative diseases, osteoporosis, trauma, or deformities. CBT showed similar clinical results to TT for visual analogue scale (VAS), Oswestry disability index (ODI), Japanese Orthopedic Association Score (JOA), and surgical time, but superior results for blood loss, screw loosening, and pseudarthrosis. The authors reported two cases of screw breakage in CBT that were not repeated with the use of screws of a larger diameter $(5.5 \mathrm{~mm}$ instead of $4.75 \mathrm{~mm}$ ). Furthermore, in a prospective study of 60 patients with spondylolisthesis (30 CBT and 30 TT with minimally invasive spine surgery), the CBT patients showed a significantly lower rate of screw loosening and loss of correction, and CBT was shown to be less invasive than TT, as measured by creatine phosphokinase (CPK) values [29].

Iwatsuki et al. [8] proposed an isthmus-guided approach for CBT (IGCBT) to avoid the complications associated with this pathway and compared it with CBT. No complications occurred and only one screw was misplaced with the IGCBT technique compared to four misplaced screws with the traditional CBT. Ohkawa et al. [30] subsequently used this procedure and compared CPK levels between the original CBT and IGCBT, showing improved results with the latter. They reported $4 \%$ screw misplacement in 12 patients (22\%), without major complications.

Mizuno et al. [31] investigated patients with spondylolisthesis and CBT fixation with posterior lumbar inter- 


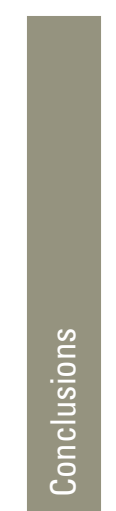

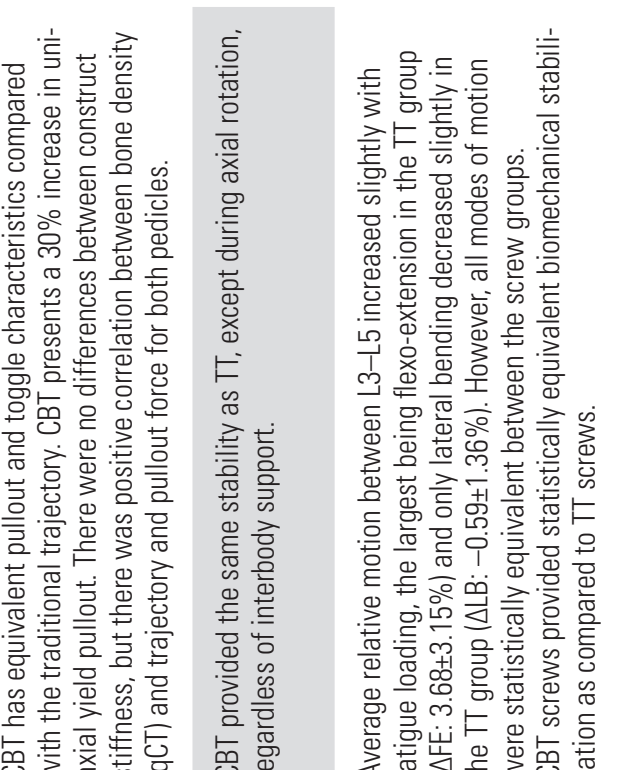

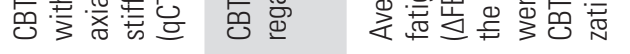
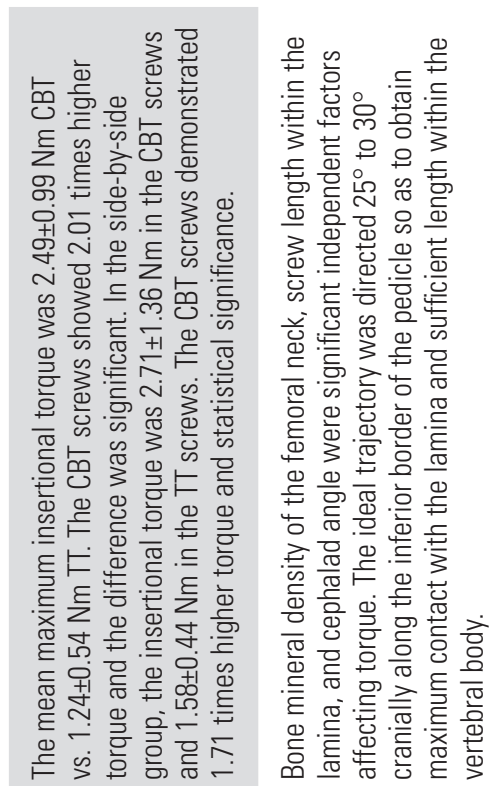

至
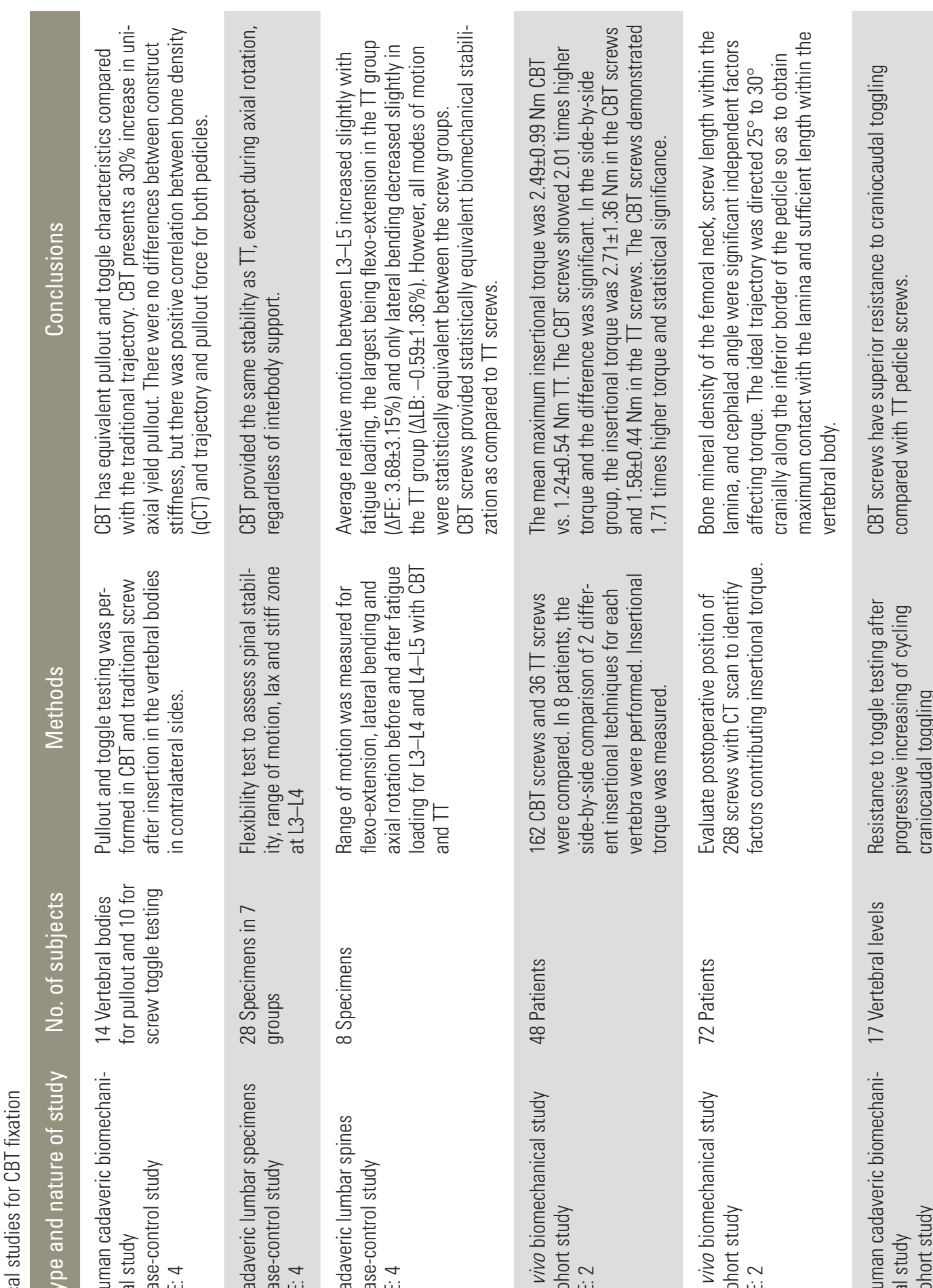

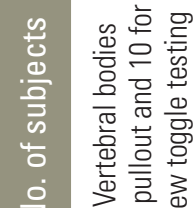 \\ 之o}

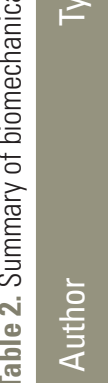

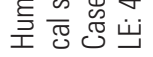

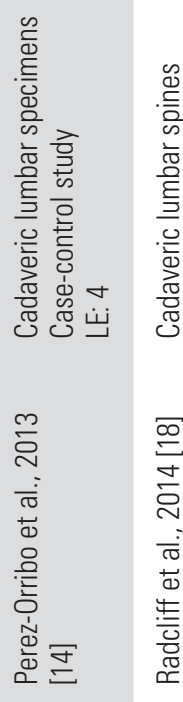

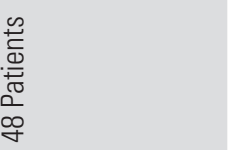

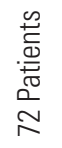
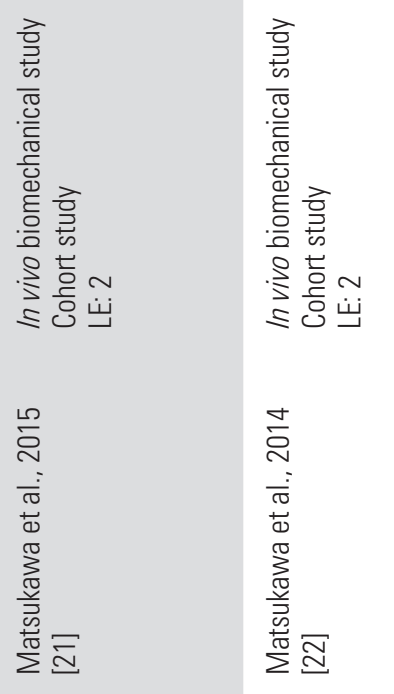

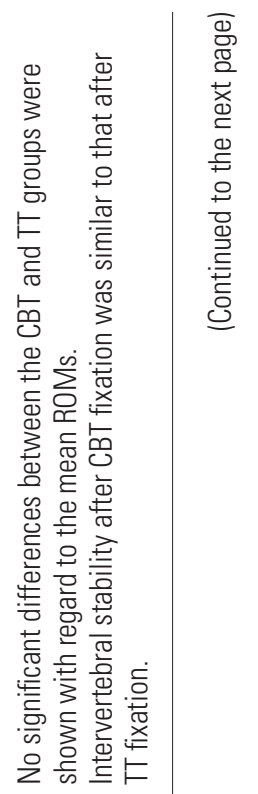

흔
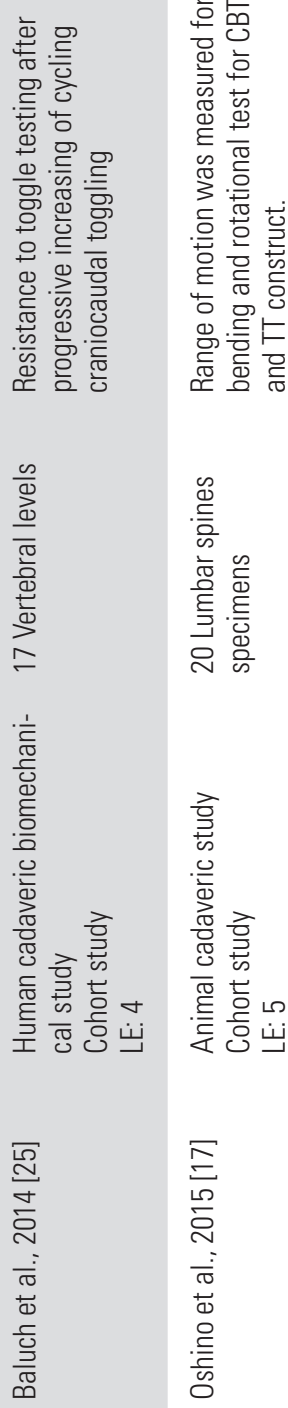


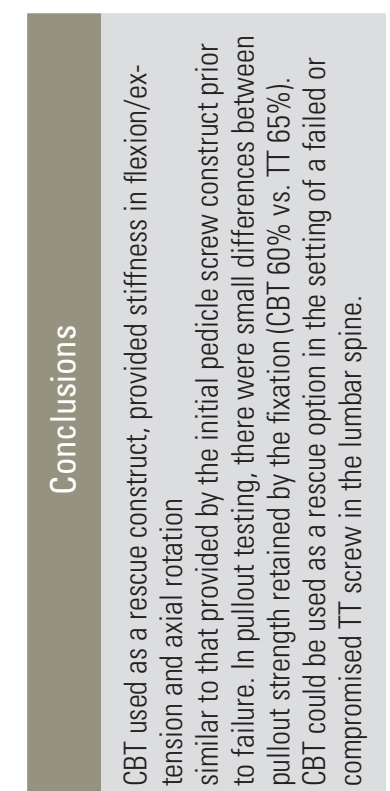

ติํㅇㅇ

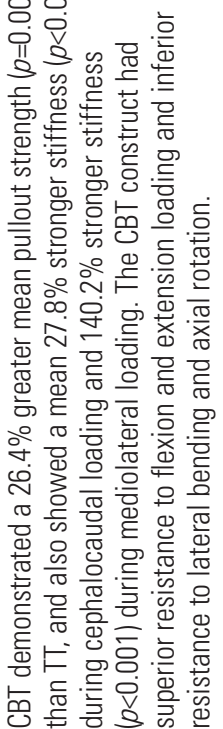

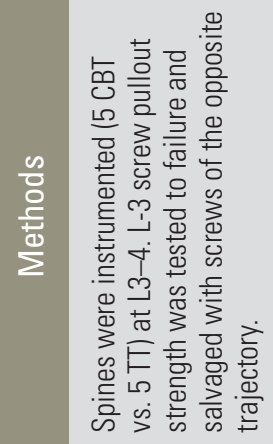

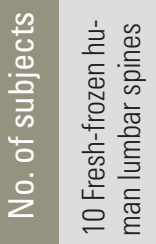

를

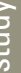

흐

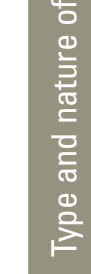

妾

空

융

芩

萱 응

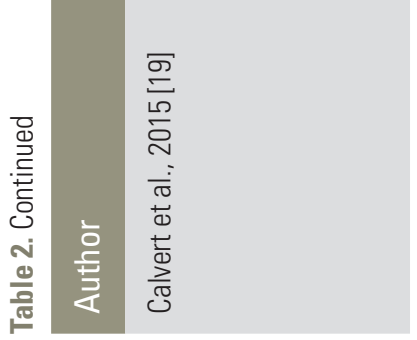

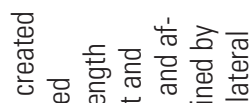

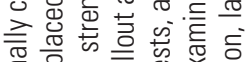

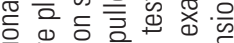

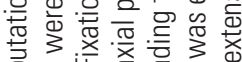

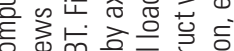

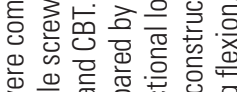

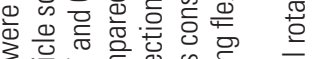

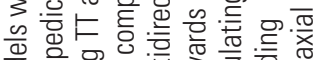

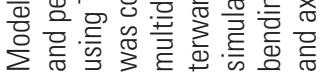
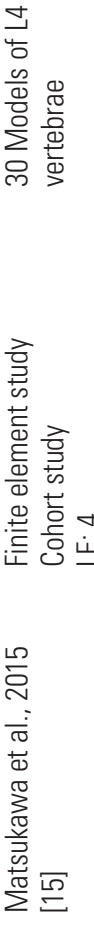

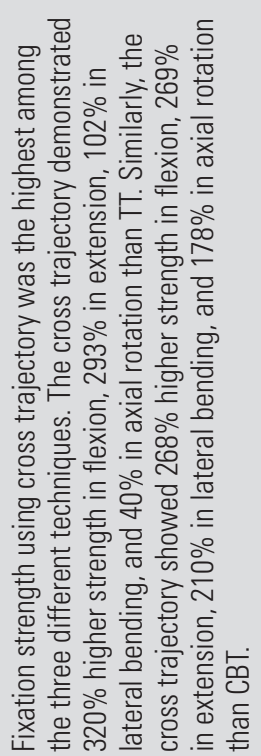

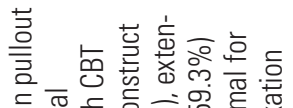

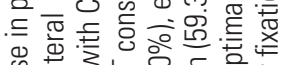
\& 뜨 350.

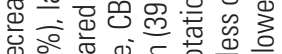
응 $\delta$ 을

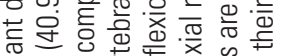

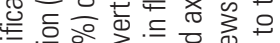

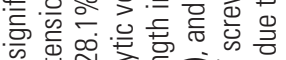
क क्य

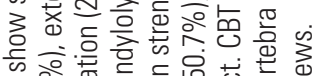

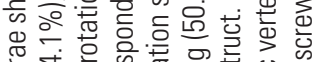

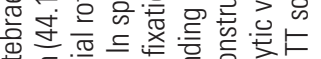

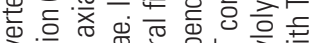

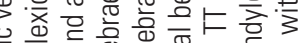

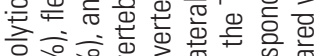

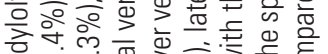
言穴少

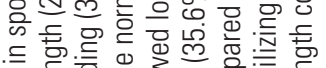

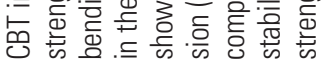

वृ

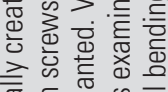

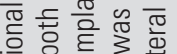

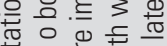

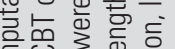

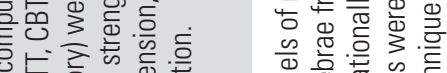

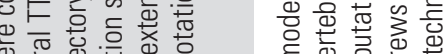

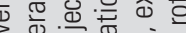

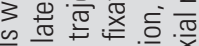

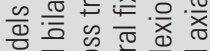

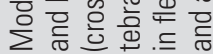

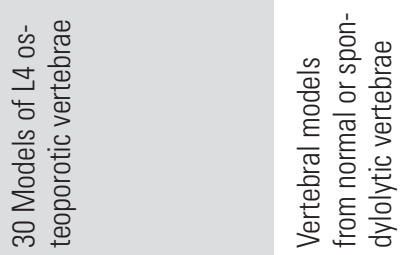

틀 휼

要

क्षे 竧离 등

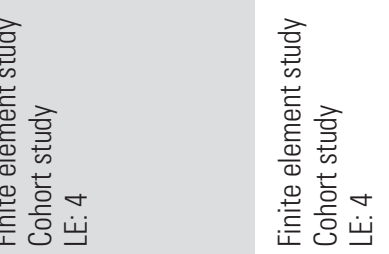
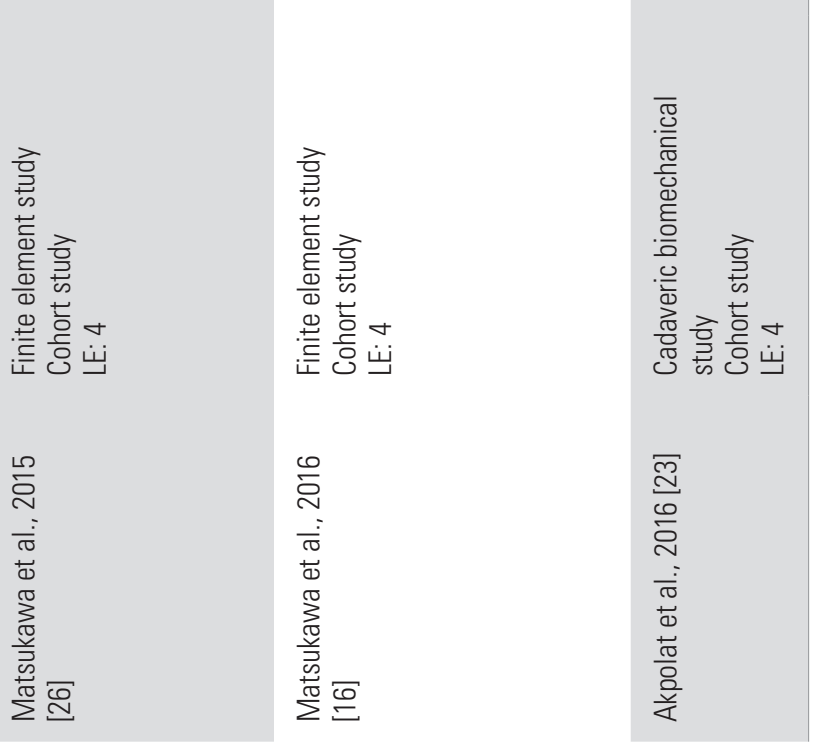

훙 몰

क्ष

ब号言 吉

这语

过 은

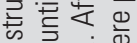

ธㅎㅎ혛ํ

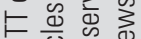

흥응

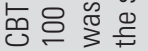
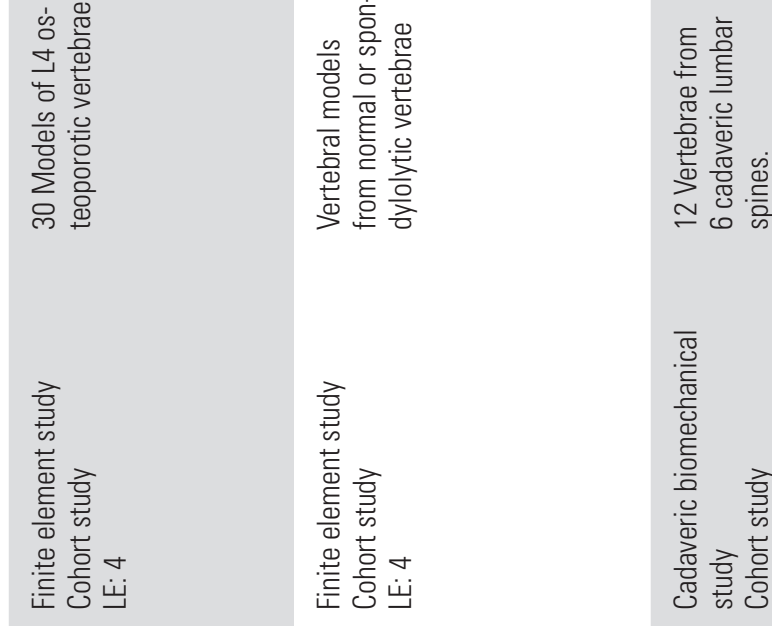


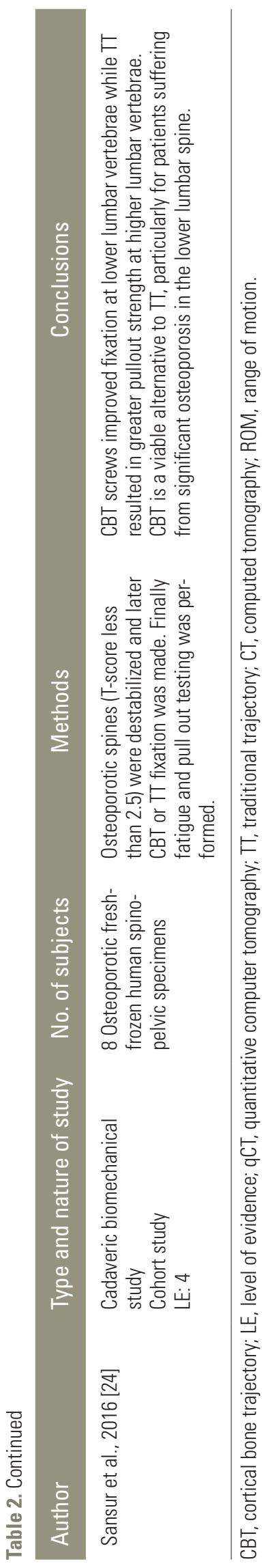

body fusion (PLIF) or transforaminal lumbar interbody fusion. This revealed one intraoperative complication due to a cortical bone fracture, but this was not associated with neurological deficit. At 20 months' follow-up, there were no signs of screw loosening, although four screws (8.3\%) had perforated the pedicle wall without clinically adverse effects. Okudaira et al. compared PLIF versus mid-line lumbar fusion with CBT and showed significant benefits with CBT in surgical time and blood loss, with similar clinical outcomes. There were no complications associated with CBT, whereas in the PLIF group, there was one wound infection with neural injury. The authors concluded that CBT was less invasive, requiring less exposure, and that recovery was faster (data not published).

Rodriguez et al. [32] proposed a double-fixation system in patients with adjacent-segment lumbar disease using CBT without removing the previous screws. No complications and good clinical outcomes were recorded at 6 months' follow-up, with clinical improvement and radiographic fusion. Like Ueno et al. [28] and Rodriguez et al. [32], Takata et al. [33] also presented a hybrid technique in which TT was used for caudal segments and CBT for cranial vertebrae. They showed that this hybrid technique was less invasive than TT because it reduced muscular retraction in the upper level.

Pacione et al. [34] published a case report of an 83-yearold woman with osteoporotic L4 compression treated with kyphoplasty, L4 decompression, and CBT fixation on L3 and L5 that needed to be rescued 3 months later with kyphoplasty after L3 compression with the standard technique, because CBT enabled the usual pedicle pathway without complications. Glennie et al. [35] were the first to report complications with CBT after a 1-year followup. Eight patients underwent operations with CBT; at 1-year follow-up, two had undergone revision surgery, five showed screw loosening, and four failed to maintain reduction on radiographic control. The authors concluded that CBT should be evaluated at medium- or long-term clinical follow-up to validate outcome measures and check for complications. Other series have reported similar complication incidences: Patel et al. [36] reported complications in five out of 22 patients (13.6\%) and Cheng et al. [37] reported two pars and pedicle fractures and two instances of early screw loosening in 22 patients. A subsequent cadaveric study by these authors revealed the proportions of pars and pedicle fractures to be $2.7 \%$ and $16.2 \%$, deviations which resulted in gross loosening. These results were 
similar to those of the study by Ninomiya et al. [38], which evaluated screw loosening with and without the presence of a clear zone around the screws in patients with CBT fixation. Clear zones were observed around six screws (5.5\%) in five patients (26.3\%), showing better results than those of previous studies. This group also compared radiological results of slippage correction and lordosis change 1 year after surgery, with significant improvement compared with preoperative values, unlike with TT [39]. Snyder et al. [40] reported a study with 79 patients that had CBT screws with or without other fixation techniques; they observed only 10 complications in seven patients: two hardware failures, two cases of pseudoarthrosis, two pulmonary embolisms, two deep vein thromboses, a wound infection, and an epidural hematoma. Surgical intervention was required for both pseudoarthroses, the wound infection, and the epidural hematoma. Mori et al. [41] reported oneyear follow-up data for CBT procedures, showing good morphometric and clinical results after surgery without major complications; however, the follow-up revealed apparent non-union in $9.4 \%$ (three) of the patients, which was a higher rate than that for TT $[42,43]$. Dabbous et al. [44] also found good results with CBT procedures for intraoperative time and blood loss, good recovery in terms of ODI score and walking distance without medication, and a reduction in analgesic medication, with $44 \%$ of patients ceasing medication. They found no major complications; minor complications were a durotomy, a pedicle fracture, and a cage migration, with only the former related to the technique due to the space limitations imposed by minimally invasive surgery (MIS). Hung et al. [45] measured fat infiltration after CBT or TT fixation by postoperative magnetic resonance imaging; they found no significant differences in clinical outcome or perioperative parameters, although minor postoperative blood loss, operative time, and hospital stay were reduced with CBT. Fat infiltration was higher with TT (Table 3) [27-41,44-48].

New articles about CBT have been published in the last few months. Orita et al. [46] described percutaneous CBT with better results measured with a VAS at 6 months compared to percutaneous TT, with a shorter time of fluoroscopy and skin incision. Ashayeri et al. [47] used a hybrid technique for congenital multilevel spinal non-segmentation, concluding that CBT could improve pedicle screw fixation when bone quality was suboptimal or pedicle anatomy was distorted. Sakaura et al. [48] compared CBT with PLIF versus TT with PLIF and concluded that the
JOA were significantly better in the CBT group and that there were fewer cases of symptomatic adjacent-segment disease (three [3.2\%] with CBT vs. nine [11\%] with TT, $p<0.05)$, with no differences in solid spinal fusion.

\section{Discussion}

In 1986, Roy-Camille et al. [6] proposed a vertical trajectory that did not follow the pedicle axis and contacted a greater proportion of cortical bone at its end point. However, until Sterba et al. [5] reported on its improved biomechanical properties, the vertical straight pathway was not used as a conventional technique. Anatomical studies have demonstrated that CBT enhanced screw purchase and interface strength through increasing thread contact with cortical bone [4,7-9]. Although CBT uses shorter and smaller-diameter screws compared to TT, it has shown better results in biomechanical studies for pullout strength, insertional torque, greater stiffness during cephalocaudal and mediolateral loading, and a superior resistance to flexion/extension; conversely, it is inferior with regard to lateral bending and axial rotation $[3,14,15,18,21,27]$. The benefits were especially important in patients with osteoporosis or in lower lumbar vertebrae where cancellous bone is more important $[3,24]$. Biomechanical studies have also demonstrated greater immediate stability with CBT screws due to the higher insertional torque [21]. However, other studies have shown worse results with CBT in terms of resistance to cycling loading [23] and decreased pullout strength, flexion, extension, lateral bending, and axial rotation compared to the TT construct in spondylolytic vertebrae [16]. However, clinical evidence does not support this negative conclusion from Matsukawa et al. [16], and instead shows good outcomes without major complications [8,29$33,35,38,39,41,44-46,48]$. Biomechanical studies provide poor evidence in support of clinical outcomes, providing only indirect information which suggests that CBT is associated with less screw loosening and improved fixation after surgery, with the vast majority of these studies seeming to agree with its biomechanical advantages.

Prior to Santoni et al.s proposal for CBT [3], clinical evidence for mediolateral fixation was described by Steel et al. [27] for thoracolumbar fractures, with good results. Since 2009, 22 clinical series or case reports have been reported and interest in CBT is growing. The majority of these showed favorable clinical results, with good clinical 


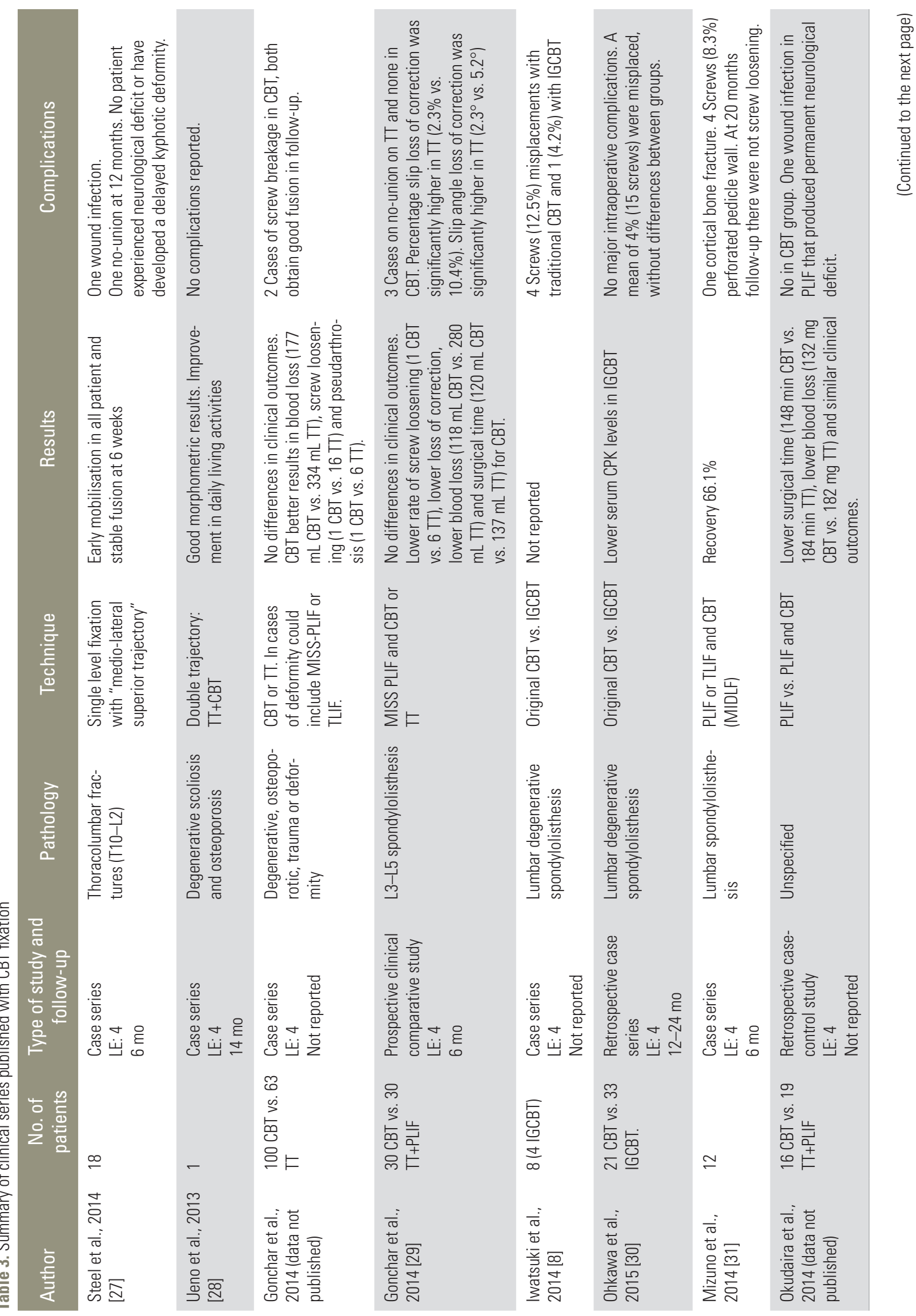




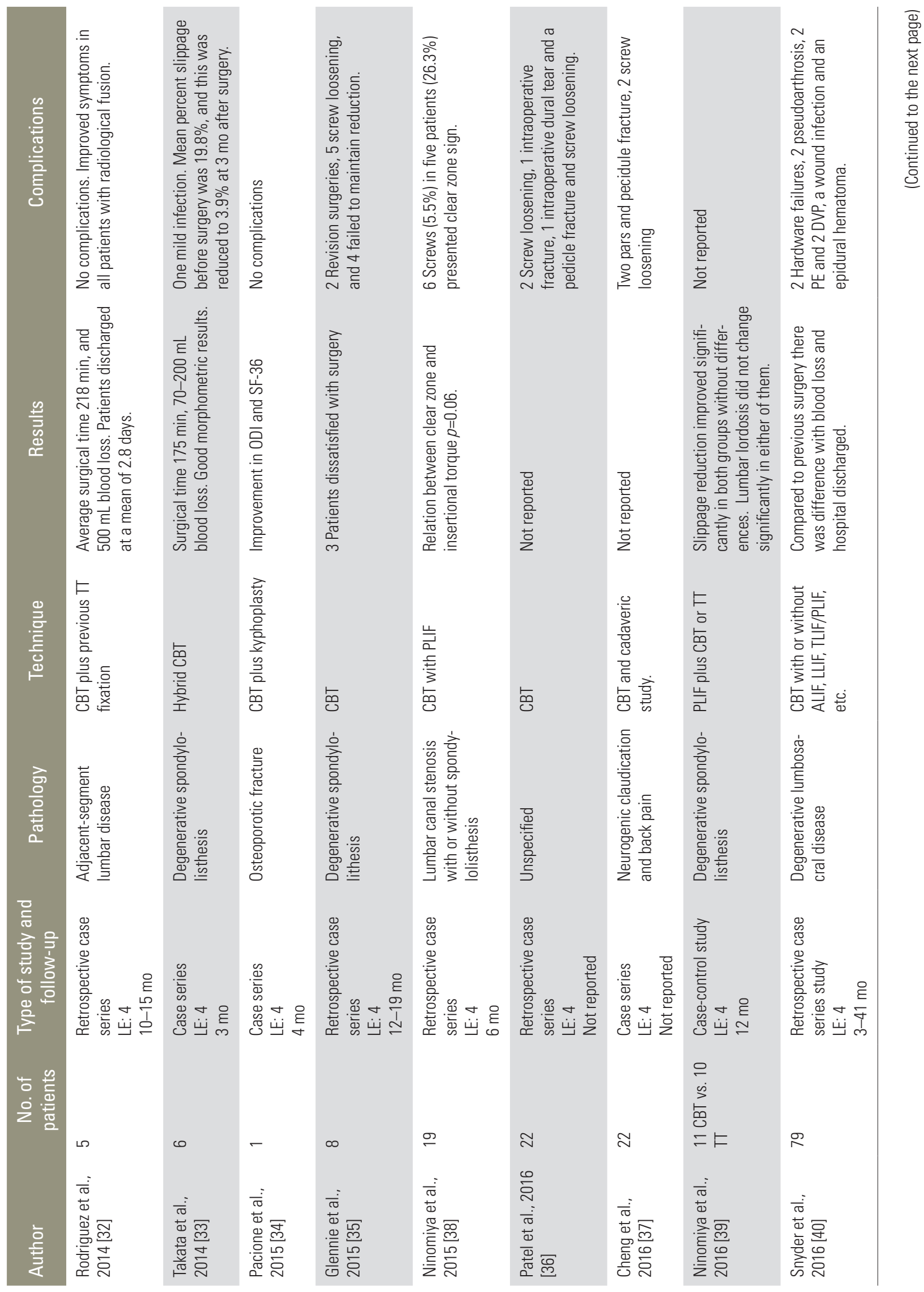




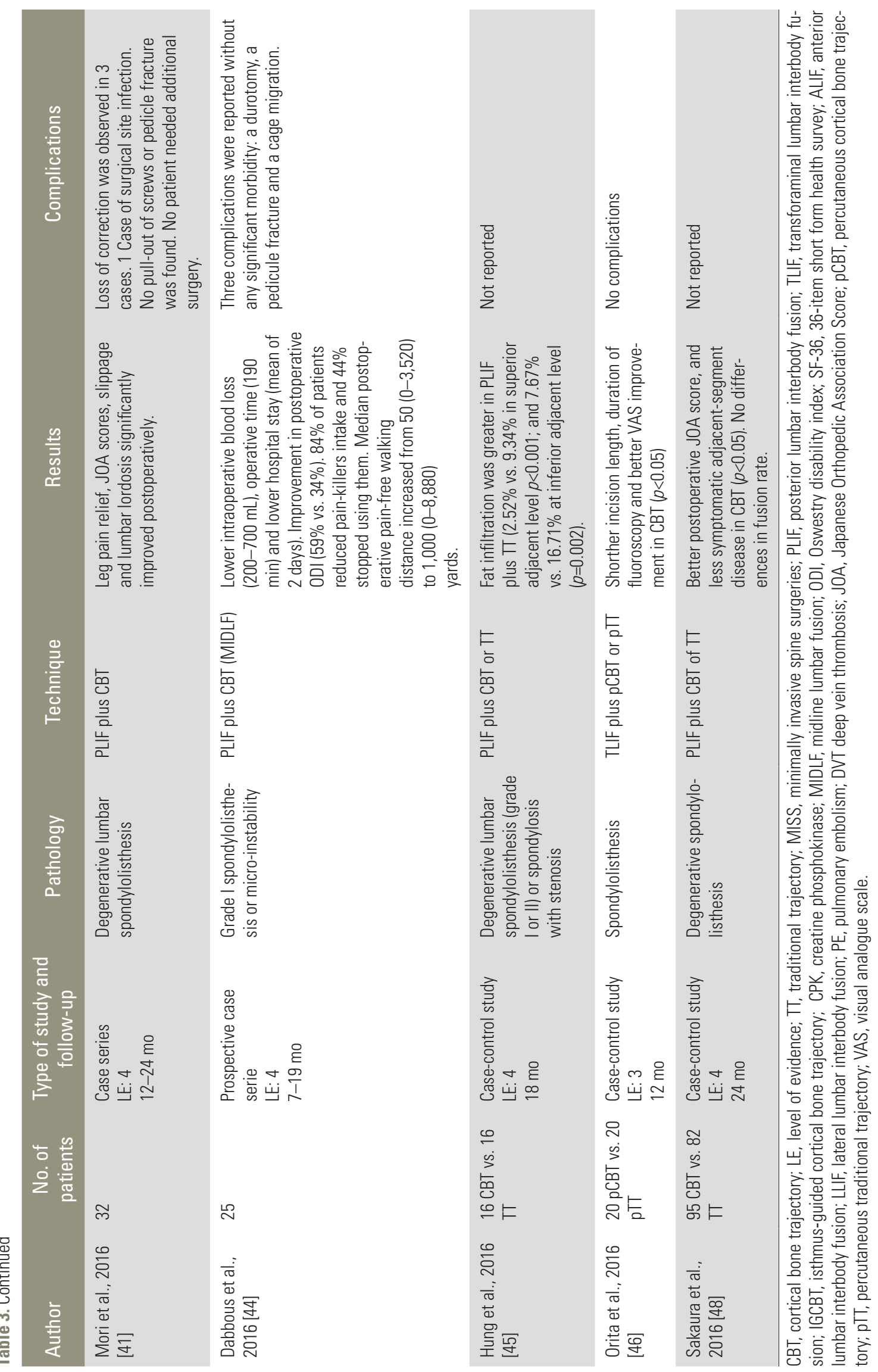


outcomes and better results for blood loss, surgical time, time to hospital discharge, and morphometric corrections [28,29-34,40-43]. Clinical outcomes for CBT were similar to those for TT, with better perioperative parameters, which can lead to fewer complications [40]. CBT is also less invasive, as measured by serum or clinical parameters, such as incision length $[30,46]$. However, although these data show a theoretical benefit of CBT fixation, over the last few years, some authors have published clinical series reporting high complication rates. We differentiated complications related to screw loosening or misplacement from those related to clinical results. Results related to screw loosening are not clear in clinical series, because clear zone, as a sign of screw loosening, has been observed to disappear in two-thirds of the cases after a 3-year follow-up. In this context, the results of Ninomiya et al. [38], who did not observe significant screw loosening at 6 months' follow-up, contrasted with those from the series reported by Glennie et al. [35], with $62 \%$ screw loosening; however, this high level was not reflected in other studies, where the screw loosening rate was estimated at around $0 \%-16.2 \%[36,37,40,41]$. Construct failure appears to be around $2.5 \%$ [40], and pedicle fracture, which is a frequent complication with CBT, has an incidence of around $4 \%(0 \%-8.3 \%)[30,36,37,41,44]$. Screw misplacement is more frequent with CBT than with TT, as shown in systematic reviews of neuronavigation systems, in which TT showed misplacement at around $10 \%$ in the worst cases [49], whereas pedicle fracture could reach $6.6 \%$ with TT [50]. The incidence of misplacement with CBT has been reported to be around $4 \%-12.5 \%[8,30]$, which does not represent an important difference from TT. Clinical complications were not frequent compared to those with other techniques described (0\%-8.1\%) [27,28,33,36,40,41,44]. Note that, in most of the studies, the follow-up period was short (median, 12 months); this could result in the underestimation of posterior complications, especially those due to screw loosening and non-union, as well as postoperative pars and pedicle fractures. In contrast, clinical outcomes with CBT were at least as good as those with TT, and new studies have reported better results for CBT $[29,44,46,48]$.

CBT has been shown to have applications for various pathologies, such as the double-fixation system [28], hybrid techniques for avoiding major exposure [33] or for congenital spinal deformation [47], treatment of adjacent segment disease [32], in combination with other tech- niques such as kyphoplasty [34], or the recently proposed percutaneous CBT [46]. However, these have been reported only as case studies and the indication has not been clearly elucidated. Sakaura et al. [48] reported a minor rate of adjacent segment disease in their series with CBT, but in the other cases, the main indications were to obtain greater rigidity of fixation using $\mathrm{CBT}$ in combination with TT $[28,32]$, but also CBT can be used to avoid TT in case it was previously used for kyphoplasty or for removing pedicle screws previously placed in that position [32,34], or to achieve adequate vertebral fixation with minor exposure $[33,46]$. It should also be emphasized that the doublefixation system demonstrated better strength in flexion, extension, lateral bending, and axial rotation compared to CBT or TT alone [26].

However, most of the studies published to date have been retrospective case series or case-control studies. Prospective evidence on the CBT technique is scarce, making it difficult to reach a definitive conclusion about its superiority over TT.

In summary, it is our opinion that the majority of the literature confirms that CBT is a safe technique that can improve results in some situations compared to traditional techniques. The vast majority of authors found that, because CBT needs less lateral exposure as there is no need to reach the transverse process, it could improve perioperative parameters such as blood loss, surgical time, or hospital stay [29,31-33,40,44], and result in lower levels of CPK and postoperative fat infiltration [29,31,45]; it could therefore benefit patients where MIS techniques are more suitable, such as for an obese population [4]. However, these potential benefits should be attributed not only to the lesser exposure but also to an appropriate selection of patients [44]. We also think that CBT should be considered with caution as a new technique. Although Dabbous et al. [44] reported that results were favorable even during the learning curve, a period of previous training is required before this technique is offered to patients, particularly because the incidence of pars of pedicle fracture and misplacement is not negligible. CBT presents good biomechanical parameters compared to TT, opening the field to new applications for this technique; however, the technique was initially devised for osteoporotic patients, but fewer clinical studies have been conducted with this group of patients $[21,34,36]$. Furthermore, although in this article we have tried to summarize all the information about CBT published to date, we emphasize that 
the majority of the studies offer weak evidence because most involved small cohorts, case series, clinical cases, or comparisons with historical control groups. Thus, further investigation of CBT must involve randomized controlled trials or homogeneous systematic studies rather than lowevidence studies. Finally, most of the previous studies compared CBT with other techniques, and most of the cases that have compared it with TT also presented the PLIF technique. The study by Sakaura et al. [48] is one of the latest to show good results. However, to date, few studies have compared CBT with TT alone.

\section{Conclusions}

CBT is increasingly used, and is a new and interesting minimal invasive technique that is demonstrating good results with acceptable morbidity. Various new applications have been proposed. However, more clinical studies are required to clarify several aspects of this technique.

\section{Conflict of Interest}

No potential conflict of interest relevant to this article was reported.

\section{References}

1. El Saman A, Meier S, Sander A, Kelm A, Marzi I, Laurer $\mathrm{H}$. Reduced loosening rate and loss of correction following posterior stabilization with or without PMMA augmentation of pedicle screws in vertebral fractures in the elderly. Eur J Trauma Emerg Surg 2013;39:455-60.

2. Galbusera F, Volkheimer D, Reitmaier S, BergerRoscher N, Kienle A, Wilke HJ. Pedicle screw loosening: a clinically relevant complication? Eur Spine J 2015;24:1005-16.

3. Santoni BG, Hynes RA, McGilvray KC, et al. Cortical bone trajectory for lumbar pedicle screws. Spine J 2009;9:366-73.

4. Song T, Hsu WK, Ye T. Lumbar pedicle cortical bone trajectory screw. Chin Med J (Engl) 2014;127:380813.

5. Sterba W, Kim DG, Fyhrie DP, Yeni YN, Vaidya R. Biomechanical analysis of differing pedicle screw insertion angles. Clin Biomech (Bristol, Avon) 2007;22:385-91.
6. Roy-Camille R, Saillant G, Mazel C. Plating of thoracic, thoracolumbar, and lumbar injuries with pedicle screw plates. Orthop Clin North Am 1986;17:14759.

7. Li B, Jiang B, Fu Z, Zhang D, Wang T. Accurate determination of isthmus of lumbar pedicle: a morphometric study using reformatted computed tomographic images. Spine (Phila Pa 1976) 2004;29:243844.

8. Iwatsuki K, Yoshimine T, Ohnishi Y, Ninomiya K, Ohkawa T. Isthmus-guided cortical bone trajectory for pedicle screw insertion. Orthop Surg 2014;6:2448.

9. Mai HT, Mitchell SM, Hashmi SZ, Jenkins TJ, Patel AA, Hsu WK. Differences in bone mineral density of fixation points between lumbar cortical and traditional pedicle screws. Spine J 2016;16:835-41.

10. Matsukawa K, Yato Y, Nemoto O, Imabayashi H, Asazuma T, Nemoto K. Morphometric measurement of cortical bone trajectory for lumbar pedicle screw insertion using computed tomography. J Spinal Disord Tech 2013;26:E248-53.

11. Matsukawa K, Yato Y, Kato T, Imabayashi H, Asazuma T, Nemoto K. Cortical bone trajectory for lumbosacral fixation: penetrating S-1 endplate screw technique: technical note. J Neurosurg Spine 2014;21:203-9.

12. Matsukawa K, Yato Y, Hynes RA, et al. Cortical bone trajectory for thoracic pedicle screws: a technical note. Clin Spine Surg 2017;30:E497-504.

13. Zhang H, Ajiboye RM, Shamie AN, Wu Q, Chen Q, Chen W. Morphometric measurement of the lumbosacral spine for minimally invasive cortical bone trajectory implant using computed tomography. Eur Spine J 2016;25:870-6.

14. Perez-Orribo L, Kalb S, Reyes PM, Chang SW, Crawford NR. Biomechanics of lumbar cortical screw-rod fixation versus pedicle screw-rod fixation with and without interbody support. Spine (Phila Pa 1976) 2013;38:635-41.

15. Matsukawa K, Yato Y, Imabayashi H, Hosogane N, Asazuma T, Nemoto K. Biomechanical evaluation of the fixation strength of lumbar pedicle screws using cortical bone trajectory: a finite element study. J Neurosurg Spine 2015;23:471-8.

16. Matsukawa K, Yato Y, Imabayashi H, Hosogane N, Asazuma T, Chiba K. Biomechanical evaluation of 
lumbar pedicle screws in spondylolytic vertebrae: comparison of fixation strength between the traditional trajectory and a cortical bone trajectory. J Neurosurg Spine 2016;24:910-5.

17. Oshino H, Sakakibara T, Inaba T, Yoshikawa T, Kato T, Kasai Y. A biomechanical comparison between cortical bone trajectory fixation and pedicle screw fixation. J Orthop Surg Res 2015;10:125.

18. Radcliff K, Klocke N, Harris J, et al. Simulating the long-term biomechanical performance of cortical screws: can a more MIS screw option provide equivalent stability as traditional pedicle screws? Proceeding of SMISS Global Forum 2014; 2014 Sep 19-21; Miami, FL, USA.

19. Calvert GC, Lawrence BD, Abtahi AM, Bachus KN, Brodke DS. Cortical screws used to rescue failed lumbar pedicle screw construct: a biomechanical analysis. J Neurosurg Spine 2015;22:166-72.

20. Zdeblick TA, Kunz DN, Cooke ME, McCabe R. Pedicle screw pullout strength. Correlation with insertional torque. Spine (Phila Pa 1976) 1993;18:16736.

21. Matsukawa K, Taguchi E, Yato Y, et al. Evaluation of the fixation strength of pedicle screws using cortical bone trajectory: what is the ideal trajectory for optimal fixation? Spine (Phila Pa 1976) 2015;40:E873-8.

22. Matsukawa K, Yato $\mathrm{Y}$, Kato T, Imabayashi $\mathrm{H}$, Asazuma T, Nemoto K. In vivo analysis of insertional torque during pedicle screwing using cortical bone trajectory technique. Spine (Phila Pa 1976) 2014;39:E240-5.

23. Akpolat YT, Inceoglu S, Kinne N, Hunt D, Cheng WK. Fatigue performance of cortical bone trajectory screw compared with standard trajectory pedicle screw. Spine (Phila Pa 1976) 2016;41:E335-41.

24. Sansur CA, Caffes NM, Ibrahimi DM, et al. Biomechanical fixation properties of cortical versus transpedicular screws in the osteoporotic lumbar spine: an in vitro human cadaveric model. J Neurosurg Spine 2016;25:467-76.

25. Baluch DA, Patel AA, Lullo B, et al. Effect of physiological loads on cortical and traditional pedicle screw fixation. Spine (Phila Pa 1976) 2014;39:E1297-302.

26. Matsukawa K, Yato Y, Imabayashi H, Hosogane N, Asazuma T, Nemoto K. Biomechanical evaluation of cross trajectory technique for pedicle screw insertion: combined use of traditional trajectory and cortical bone trajectory. Orthop Surg 2015;7:317-23.

27. Steel TR, Rust TM, Fairhall JM, Mobbs RJ. Monosegmental pedicle screw fixation for thoraco-lumbar burst fracture. J Bone Joint Surg Br 2004;86 (Suppl 4):458.

28. Ueno M, Imura T, Inoue G, Takaso M. Posterior corrective fusion using a double-trajectory technique (cortical bone trajectory combined with traditional trajectory) for degenerative lumbar scoliosis with osteoporosis: technical note. J Neurosurg Spine 2013;19:600-7.

29. Gonchar I, Kotani Y, Matsui Y, Miyazaki T, Kasemura T, Masuko T. Experience of 100 consecutive spine reconstructions using cortical bone trajectory (CBT) screws vs traditional pedicle screws. Proceeding of SMISS Global Forum 2014; 2014 Sep 19-21; Miami, FL, USA.

30. Ohkawa T, Iwatsuki K, Ohnishi Y, Ninomiya K, Yoshimine T. Isthmus-guided cortical bone trajectory reduces postoperative increases in serum creatinine phosphokinase concentrations. Orthop Surg 2015;7:232-8.

31. Mizuno M, Kuraishi K, Umeda Y, Sano T, Tsuji M, Suzuki H. Midline lumbar fusion with cortical bone trajectory screw. Neurol Med Chir (Tokyo) 2014;54:716-21.

32. Rodriguez A, Neal MT, Liu A, Somasundaram A, Hsu W, Branch CL Jr. Novel placement of cortical bone trajectory screws in previously instrumented pedicles for adjacent-segment lumbar disease using CT image-guided navigation. Neurosurg Focus 2014;36:E9.

33. Takata Y, Matsuura T, Higashino K, et al. Hybrid technique of cortical bone trajectory and pedicle screwing for minimally invasive spine reconstruction surgery: a technical note. J Med Invest 2014;61:38892.

34. Pacione D, Kim I, Wilson TA, Frempong-Boadu A. Cortical screw trajectory for instrumentation and fusion in the setting of osteopathic compression fracture allows for percutaneous kyphoplasty for adjacent level compression fractures. J Clin Neurosci 2015;22:899-904.

35. Glennie RA, Dea N, Kwon BK, Street JT. Early clinical results with cortically based pedicle screw trajectory for fusion of the degenerative lumbar spine. J Clin Neurosci 2015;22:972-5. 
36. Patel SS, Cheng WK, Danisa OA. Early complications after instrumentation of the lumbar spine using cortical bone trajectory technique. J Clin Neurosci 2016;24:63-7.

37. Cheng WK, Akpolat YT, Inceoglu S, Patel S, Danisa OA. Pars and pedicle fracture and screw loosening associated with cortical bone trajectory: a case series and proposed mechanism through a cadaveric study. Spine J 2016;16:e59-65.

38. Ninomiya K, Iwatsuki K, Ohnishi Y, Ohkawa T, Yoshimine T. Clear zone formation around screws in the early postoperative stages after posterior lumbar fusion using the cortical bone trajectory technique. Asian Spine J 2015;9:884-8.

39. Ninomiya K, Iwatsuki K, Ohnishi Y, Yoshimine T. Radiological evaluation of the initial fixation between cortical bone trajectory and conventional pedicle screw technique for lumbar degenerative spondylolisthesis. Asian Spine J 2016;10:251-7.

40. Snyder LA, Martinez-Del-Campo E, Neal MT, et al. Lumbar spinal fixation with cortical bone trajectory pedicle screws in 79 patients with degenerative disease: perioperative outcomes and complications. World Neurosurg 2016;88:205-13.

41. Mori K, Nishizawa K, Nakamura A, Imai S. Shortterm clinical result of cortical bone trajectory technique for the treatment of degenerative lumbar spondylolisthesis with more than 1-year follow-up. Asian Spine J 2016;10:238-44.

42. Sears W. Posterior lumbar interbody fusion for degenerative spondylolisthesis: restoration of sagittal balance using insert-and-rotate interbody spacers. Spine J 2005;5:170-9.

43. Nemoto O, Asazuma T, Yato Y, Imabayashi H, Yasuoka H, Fujikawa A. Comparison of fusion rates following transforaminal lumbar interbody fusion using polyetheretherketone cages or titanium cages with transpedicular instrumentation. Eur Spine J 2014;23:2150-5.

44. Dabbous B, Brown D, Tsitlakidis A, Arzoglou V. Clinical outcomes during the learning curve of MIDline Lumbar Fusion (MIDLF(R)) using the cortical bone trajectory. Acta Neurochir (Wien) 2016;158:1413-20.

45. Hung CW, Wu MF, Hong RT, Weng MJ, Yu GF, Kao $\mathrm{CH}$. Comparison of multifidus muscle atrophy after posterior lumbar interbody fusion with conventional and cortical bone trajectory. Clin Neurol Neurosurg 2016;145:41-5.

46. Orita S, Inage K, Kubota G, et al. One-year prospective evaluation of the technique of percutaneous cortical bone trajectory spondylodesis in comparison with percutaneous pedicle screw fixation: a preliminary report with technical note. J Neurol Surg A Cent Eur Neurosurg 2016;77:531-7.

47. Ashayeri K, Nasser R, Nakhla J, Yassari R. The use of a pedicle screw-cortical screw hybrid system for the surgical treatment of a patient with congenital multilevel spinal non-segmentation defect and spinal column deformity: a technical note. Eur Spine J 2016;25:3760-4.

48. Sakaura H, Miwa T, Yamashita T, Kuroda Y, Ohwada T. Posterior lumbar interbody fusion with cortical bone trajectory screw fixation versus posterior lumbar interbody fusion using traditional pedicle screw fixation for degenerative lumbar spondylolisthesis: a comparative study. J Neurosurg Spine 2016;25:591-5.

49. Sarwahi V, Wendolowski SF, Gecelter RC, et al. Are We Underestimating the Significance of Pedicle Screw Misplacement? Spine (Phila Pa 1976) 2016;41:E548-55.

50. Tian NF, Huang QS, Zhou P, et al. Pedicle screw insertion accuracy with different assisted methods: a systematic review and meta-analysis of comparative studies. Eur Spine J 2011;20:846-59. 